\title{
EHA Scientific Working Groups: Connecting Science and Spreading Knowledge in Hematology
}

\author{
Pieter Sonneveld ${ }^{1,2}$ \\ Correspondence: Pieter Sonneveld (e-mail: p.sonneveld@erasmusmc.nl)
}

${ }^{1}$ Department of Hematology, Erasmus MC Cancer Institute, Rotterdam, The Netherlands

${ }^{2}$ European Hematology Association Scientific Working Group Committee, The Hague, The Netherlands.

$P S$ received honoraria from Amgen, Celgene/BMS, Janssen, Karyopharm, SkylineDx.

Copyright ( 12020 the Author(s).

Published by Wolters Kluwer Health, Inc. on behalf of the European Hematology Association. This is an open access article distributed under the terms of the Creative Commons Attribution-Non Commercial-No Derivatives License 4.0 (CCBY-NC-

$N D)$, where it is permissible to download and share the work provided it is properly cited. The work cannot be changed in any way or used commercially without permission from the journal.

HemaSphere (2020) 4:2(e365)

Received: 11 February 2020 /

Accepted: 18 February 2020

Citation: Sonneveld P. EHA

Scientific Working Groups:

Connecting Science and Spreading Knowledge in Hematology.

HemaSphere, 2020;4:2. http://dx.doi. org/10.1097/HS9.0000000000000365

\section{Navigating the EHA roadmap}

In the European Union, an estimated 80 million people are affected with one of the blood disorders, which range from cancers to coagulation defects. ${ }^{1}$ To help explore and manage these diseases, the European Hematology Association (EHA) Roadmap for European Hematology Research pinpointed important priorities and needs spanning the different areas of hematology. ${ }^{1}$ The nine key sections identified within the EHA Roadmap consensus document include normal hematopoiesis, malignant lymphoid diseases, malignant myeloid diseases, anemias and related diseases, platelet disorders, blood coagulation and hemostatic disorders, transfusion medicine, infections in hematology, and hematopoietic stem cell transplantation. ${ }^{1}$

It is EHA's ambition to comprehensively represent and reflect the entire spectrum of hematology research across Europe by supporting and working in synergy with Scientific Working Groups (SWGs). SWGs are a key tool that enables EHA to connect and collaborate with experts across the whole range of hematology laid out in the EHA roadmap.

\section{Leveraging the power of SWGs}

By partnering with the expert researchers and clinicians who are members of the SWGs, EHA envisages to support science and spread knowledge in basic, translational and clinical research in hematology across Europe. The key goals of the SWGs are:

- To initiate and create scientific networks that serve under the umbrella of EHA.

- To collaborate with existing networks in specific hematology areas and connect these with EHA.

- To promote high-quality science within the EHA community and identify new innovative areas for research.

- To drive best patient care through the development of guidelines.

- To advise the EHA Board and European Affairs Committee on scientific policies and priorities in research.

Through its SWGs, EHA is undertaking activities to address current unmet needs in the hematology arena, define disease areas that warrant extra exploration and focus on new ambitions, exploring future frontiers in hematology research.

In total, there are currently 24 SWGs covering fields of hematology which are closely aligned with the nine key sections of the EHA roadmap. Structurally, these SWGs are organized into either disease-orientated or overarching groups. The topics covered by each of the 2 broad families of SWG are listed in Figure 1.

Each SWG is represented by an expert Chair and Co-chair, who are both EHA members, as well as an Executive Committee. Annual reports on the activities of each SWG are produced and published online on the EHA website.

To further support high-quality science, specific slots for SWG sessions are incorporated into the main EHA Annual Congress program. ${ }^{2}$ These 1-hour events are designed to showcase state-of-the art in the specific sector of hematology being focused on by each SWG, and collectively offer updates on a range of important areas in hematology research.

EHA also organizes dedicated scientific meetings for SWGs which follow an innovative, interactive format and incorporate the latest insights from leading hematologists in the field. Three or four of these scientific workshops are organized annually in Europe, with each meeting attracting between 80 and 150 delegates. In 2019, for instance, 4 EHA-SWG Scientific Meetings 


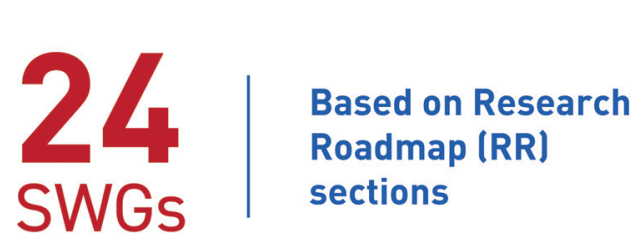

Disease-oriented SWGs

\begin{tabular}{l|l|}
\hline $\begin{array}{l}\text { Hematopoietic stem cell } \\
\text { transplantation }\end{array}$ & MS cells \\
$\begin{array}{l}\text { \& other cell-based therapies } \\
\text { \& Normal hematopoiesis }\end{array}$ & Stem cells \\
\hline & $\begin{array}{l}\text { Granulocyte \& constitutional marrow } \\
\text { failure disorders }\end{array}$ \\
\hline \multirow{3}{*}{$\begin{array}{l}\text { Malignant lymphoid } \\
\text { diseases }\end{array}$} & Lymphomas \\
\cline { 2 - 2 } & EWALL \\
\hline & CLL (ERIC) \\
\hline $\begin{array}{l}\text { Malignant myeloid } \\
\text { diseases }\end{array}$ & MM \\
\hline & AML \\
\hline & CML \\
\hline
\end{tabular}

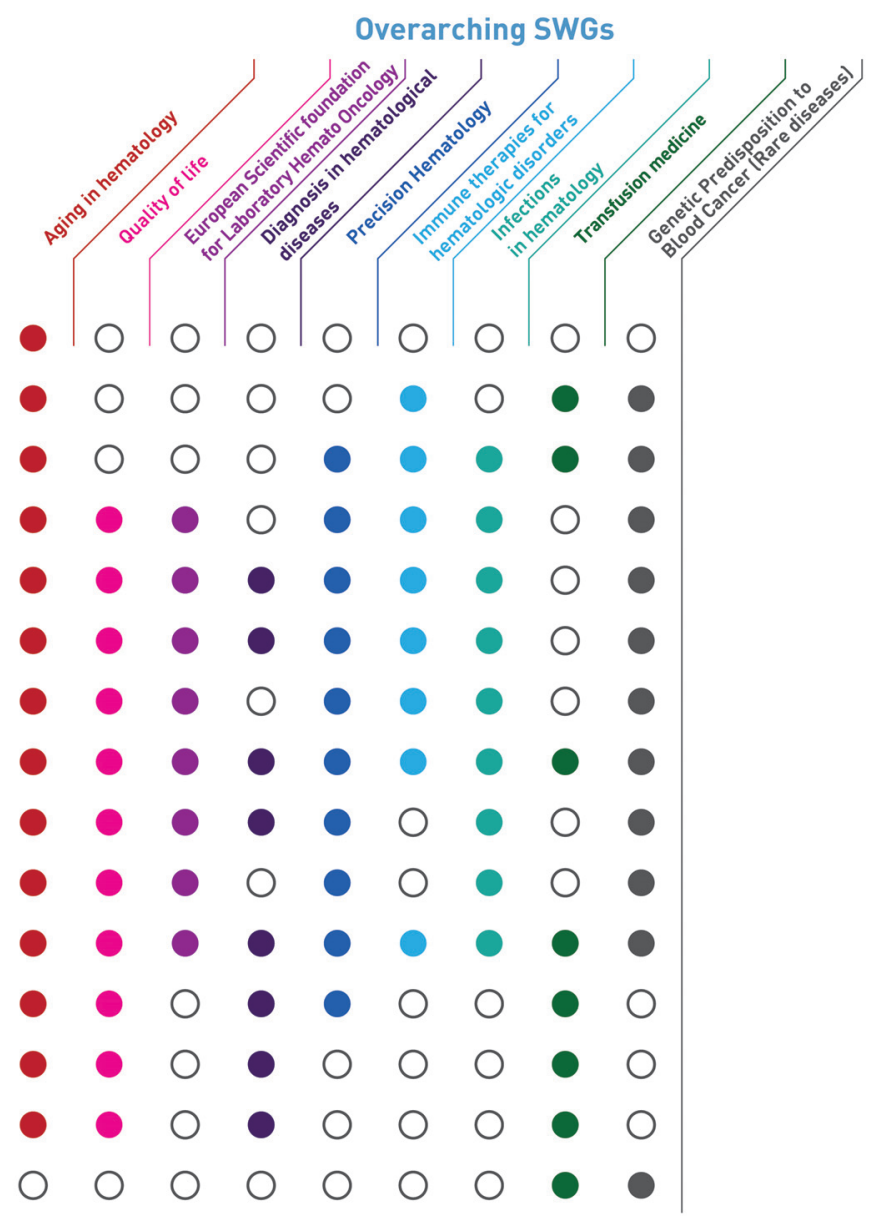

\begin{tabular}{c|l}
\hline Anemias \& related diseases & Red cells \& iron \\
\hline Platelet disorders & $\begin{array}{l}\text { Thrombocytopenia } \\
\text { \& platelet function disorders }\end{array}$ \\
\hline $\begin{array}{l}\text { Blood coagulation } \\
\text { \& hemostatic disorders }\end{array}$ & Bleeding \& thrombosis \\
\hline Pediatric hematology & Pediatric hematology \\
\hline
\end{tabular}

Figure 1. European Hematology Association Scientific Working Groups (SWGs) and topics.

were organized, including the 1st European CAR T-Cell meeting. Examples of upcoming EHA-SWG scientific meetings include:

- The EHA-SWG Scientific Meeting on Mesenchymal Stromal Cells and Tissue Homeostasis. The 4th edition of this EHASWG Scientific Meeting will span 3 days, during which participants will enhance their understanding of the key principles of tissue homeostasis, with a particular focus on stromal cells. It is organized in collaboration with EHA and the Mesenchymal Stromal Cells SWG.

- The EHA-EBMT 2nd European CAR T-Cell Meeting, which will be held in Sitges (Spain) from 30 January to 1 February 2020. This meeting is jointly organized by the EHA and the European Society for Blood and Marrow Transplantation (EBMT).

Each SWG enjoys the freedom to pursue its own specific research programs and initiatives. As the composition and scope of individual SWGs can prove extremely variable, EHA members are encouraged to consult the SWG section of the EHA website (https://ehaweb.org/research/scientific-working-groups/) for a full update on the range of activities being undertaken by each group.

\section{SWGs in action}

Key initiatives carried out by EHA have successfully leveraged the power of SWGs as networks of experts in their respective fields of hematology. Due directly to the work of SWGs, important steps forward have been taken with the development of new clinical guidelines, the establishment of relevant research collaborations, as well as providing scientific advice for policy and regulation.

A number of disease-oriented EHA SWGs have been actively involved in the guideline development process for their respective fields, helping to drive evidence-based best practice within hematology. For example, the Thrombocytopenia and Platelet Function Disorders SWG has prepared and published, with the support of EHA, consensus recommendations on the initial diagnostic approach to mild to moderate bleeding disorders, which remain a difficult group of diseases to definitively diagnose and effectively treat. This report marks the first step in an EHA initiative to develop evidence-based guidelines for specific mild and moderate bleeding disorders. ${ }^{3}$ Follow-up papers will focus on von Willebrand disease (VWD), coagulation and fibrinolytic system disorders and platelet and vascular disorders. EHA also partners when relevant with other networks and societies, such as the European Society for Medical Oncology (ESMO), to produce collaborative guidelines.

Efforts are also ongoing within the overarching SWGs to develop new guidelines and recommendations in emerging areas of hematology or key topics that are not yet covered. For example, the SWG on Aging and Hematology is working to develop clinical guidance on cardiovascular complications in older adults undergoing therapy for hematologic malignancies. 
The Quality of Life SWG is also involved in the creation and validation of a novel tool for the evaluation of patientreported outcomes (PROs) in patients with hematological malignancies (HM-PRO), which is being translated and will be available in over 10 international languages by the end of 2019.

Echoing EHA's central ethos of collaboration and partnership, SWGs are also actively participating in important initiatives within the wider hematology landscape. A prime example of this is the collaboration with the HARMONY Alliance, a publicprivate European Network of Excellence whose mission is to unlock and spread valuable knowledge on hematologic malignancies. From within EHA, the European Research Initiative on CLL (ERIC), Myelodysplastic Syndromes (MDS), Adult Acute Lymphoblastic Leukemia (EWALL), Multiple Myeloma (MM), Acute Myeloid Leukemia (AML) and the EHA Lymphoma Group $S W G$ s are all working closely with the HARMONY Alliance to harness and mine big data in order to expedite the development of improved treatment options for patients with hematological cancers.

\section{Harnessing the opportunity}

SWGs provide scientists, researchers and clinicians with the unprecedented opportunity to assume an active role in shaping the future research landscape in hematology. By supporting SWGs, EHA aims to provide a research platform that is accessible and available to all groups and researchers across the entire EHA roadmap.
Individuals currently working within hematology - from the bench to the bedside - are encouraged to become active participants in existing SWG networks that reflect their own research and clinical expertise and interests. SWG membership is open to any physician and researcher with a professional interest that mirrors that of the group itself. EHA members can connect with specific SWGs via the annual EHA congress or through EHA channels like the website. Membership Application Forms can be downloaded from the EHA-SWG Procedure and Reports webpage (https:// ehaweb.org/research/scientific-working-groups/procedure-andreports/) and submitted to SWGs@ehaweb.org. SWGs also provide a unique vehicle to drive research into new and emerging frontiers in hematology.

Through close collaboration and the sharing of knowledge under the umbrella of EHA, involvement in SWGs offers EHA members the opportunity to continue to advance and accelerate hematology research towards a brighter future.

\section{References}

1. Engert A, Balduini C, Brand A, et al. The European Hematology Association Roadmap for European Hematology Research: A Consensus Document. Haematologica. 2016;101:115-208.

2. Congress Topics. Available at: https://ehaweb.org/congress/reports/ eha24-digital-congress-report/congress-topics/. [Accessed November 28, 2019].

3. EHA. European Hematology Association issues recommendations on mild to moderate bleeding disorders. Press release. September 25, 2019. Available at: https://ehaweb.org/assets/Uploads/2019-EHApress-release-Guidelines-on-Non-Severe-Bleeding-Disorders-final-v2. pdf [Accessed November 7, 2019]. 